\title{
Clinical impact of serum bilirubin levels on kidney transplant outcomes
}

\author{
Juhan Lee ${ }^{1}$, Eun Jin Kim¹, Jae Geun Lee ${ }^{1}$, Beom Seok Kim², Kyu Ha Huh', Myoung Soo Kim¹, Soon II Kim', Yu Seun Kim', \\ Dong Jin $\mathrm{J}^{1}{ }^{1}$
}

${ }^{1}$ Division of Transplantation, Department of Surgery, Severance Hospital, Seoul, Korea

${ }^{2}$ Division of Nephrology, Department of Internal Medicine, Severance Hospital, Seoul, Korea

Background: Serum bilirubin, a potent endogenous antioxidant, has been associated with decreased risks of cardiovascular disease, diabetes, and chronic kidney disease. However, the effects of serum bilirubin on long-term kidney transplant outcomes remain undetermined.

Methods: We analyzed 1,628 patients who underwent kidney transplantations between 2003 and 2017. Total serum bilirubin levels were assessed every month for the first post-transplantation year. Patients were grouped into sex-specific quartiles according to mean serum bilirubin levels assessed between 3 and 12 months post-transplantation.

Results: Median bilirubin levels were $0.66 \mathrm{mg} / \mathrm{dL}$ (interquartile range, $0.50-0.85 \mathrm{mg} / \mathrm{dL}$ ) in males and $0.60 \mathrm{mg} / \mathrm{dL}$ (interquartile range, $0.50-0.74 \mathrm{mg} / \mathrm{dL}$ ) in females. The intra-individual variability of serum bilirubin levels was low $(9 \%)$. Serum bilirubin levels were inversely associated with graft loss, death-censored graft failure, and all-cause mortality, independent of renal function, donor status, human leukocyte antigen mismatch, and transplant characteristics. Multivariable analysis revealed that the lowest serum bilirubin quartile was associated with increased risk of graft loss (hazard ratio [HR], 2.63; 95\% confidence interval [Cl], 1.67-4.16; $P<0.001)$, death-censored graft failure ( $H R, 2.96 ; 95 \% \mathrm{Cl}, 1.62-5.40 ; \mathrm{P}<0.001)$, and all-cause mortality (HR, 2.07; 95\% $\mathrm{Cl}, 1.01-4.23 ; \mathrm{P}=0.046)$. Patients with lower serum bilirubin levels were also at greater risk of late-onset rejection and exhibited consistently lower estimated glomerular filtration rates than those with higher serum bilirubin levels.

Conclusions: Serum bilirubin levels were significantly associated with transplantation outcomes, suggesting that bilirubin could represent a therapeutic target for improving long-term transplant outcomes.

Corresponding author: Juhan Lee

E-mail: juhan1108@gmail.com

(C) The Korean Society for Transplantation

This is an Open Access article distributed under the terms of the Creative Commons Attribution Non-Commercial License (http://creativecommons.org/licenses/by-nc/4.0/) which permits unrestricted non-commercial use, distribution, and reproduction in any medium, provided the original work is properly cited. 